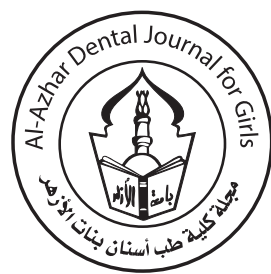

\title{
Evaluation of Chelating Potential of Chitosan Citrate and Chitosan Acetate on Intraradicular Dentin
}

\author{
Shaimaa A. Naem ${ }^{1 *}$, Mervat I. Fawzy ${ }^{2}$, Hagar A. Bastawy ${ }^{3}$
}

Codex : 34/1907

azhardentj@azhar.edu.eg

http://adjg.journals.ekb.eg

DOI: $10.21608 /$ adjg.2019.6056.1048

\section{KEYWORDS}

Chitosan acetate,

chitosan citrate,

calcium content,

intraradicular dentin.

\begin{abstract}
Purpose: This study was designed to assess the chelating capacity of chitosan acetate and chitosan citrate on intraradicular dentin using environmental scanning electron microscope (ESEM) and quantity calcium content of intraradicular dentin using energy dispersive X-ray microanalyzer (EDX). Materials and Methods: sixty freshly extracted human single rooted lower premolars were instrumented with Revo-S files till size AS 35.The samples were dispensed into 5 groups according to the final rinse used and control group (10 samples each); Group I: irrigated with $0.2 \%$ chitosan acetate, Group II: irrigated with $0.2 \%$ chitosan citrate, Group III: irrigated with $1 \%$ acetic acid, Group IV: irrigated with $1 \%$ citric acid, Group V: irrigated with 17\% EDTA and control group which was divided into;(VIa):5 samples irrigated with sterile saline and (VIb): 5 samples were neither prepared nor received any treatment. Samples were grooved longitudinally and the cleanliness of the root canals and smear layer were evaluated at three root levels using ESEM. The calcium content of intraradicular dentin of five samples from each experimental group (I,II,III,IV,V) and the samples of control group (VIa and VIb) was measured using EDX. Results: At three root levels; there was a statistical difference among the tested groups and control group in the median scores of smear layer However, there was no statistical difference in the median scores of smear layer among the tested groups. Comparing the smear layer scores within each tested group, apical level has the highest median smear layer score compared to other two levels. Regarding calcium content, the highest mean calcium content was recorded in samples treated with saline followed by samples that did not receive any irrigation. However, no statistical difference among tested groups. Conclusion: chelating potential of $0.2 \%$ chitosan acetate and $0.2 \%$ chitosan citrate is comparable to that of $17 \%$ EDTA when used as final rinse without much altering the calcium content of intraradicular dentin compared to $17 \%$ EDTA.
\end{abstract}

* Paper extracted from master thesis titled "Evaluation of Chelating Potential of Chitosan Citrate and Chitosan Acetate on Intraradicular Dentin".

1. Dentist at Ministry of Health. email: shaimaa514@yahoo.com

2. Professor of Endodontics, Endodontic Department, Faculty of Dental Medicine for Girls, Al -Azhar University.

3. Assistant Professor of Endodontics, Endodontic Department, Faculty of Dental Medicine for Girls, Al -Azhar University. 


\section{INTRODUCTION}

Instrumentation of the root canal produces a smear layer that mask the dentinal tubules. The smear layer is an amorphous irregular layer containing inorganic dentin debris and organic materials like necrotic debris, pulp tissue, microorganisms and their metabolic products ${ }^{(1)}$. It may contain bacteria, preventing the canal from being disinfected, limit the entrance of intracanal disinfectants and sealers into dentinal tubules. Thus, the elimination of this layer is crucial for long-term success of root canal treatment $^{(2)}$.

The most frequently used endodontic irrigant is sodium hypochlorite $(\mathrm{NaOCl})$ due to its bactericidal activity and ability to liquefy necrotic and vital tissue. However, $\mathrm{NaOCl}$ solutions have not effects on inorganic components of smear layer. Chelaing agents and acid solutions have been recommended for eliminating inorganic components of smear layer $^{(2)}$.

EDTA is recognized as effective chelating agent. However, severe intratubular and peritubular erosion of dentin after 10 min contact to $17 \%$ EDTA and causing irritation to periapical area when extruded from apical constriction ${ }^{(3,4)}$.

Citric acid is a chelating agent that reacts with metals to form nonionic soluble chelate. Citric acid is more compatible to tissue than EDTA. ${ }^{(5)}$ It has been reported that $17 \%$ EDTA and $10 \%$ citric acid had greater smear layer elimination rates in the coronal and middle thirds ${ }^{(6)}$.

Acetic acid is another chelating agent which can bind to calcium ion to form compounds that are easily eliminated, but it does not have a concentration of $\mathrm{H}^{+}$ions that could produce an efficient calcium elimination ${ }^{(7)}$.

Because of restrictions of all endodontic irrigants, rising better and new irrigating solutions for endodontics remains an area of great importance. Chitosan is a new irrigant which has a great deal of interest in dental field because of its biodegrad- ability, biocompatibility, non toxicity and has high chelating capacity for different metal ions in acidic environment ${ }^{(8)}$. Chitosan is a weak base, insoluble in organic solvents and water, but soluble in acidic solution as acetic acid or citric acid to form chitosan-acetate and chitosan-citrate ${ }^{(9)}$. A preliminary study evaluated the chelating properties of chitosan as a (natural polymer) in comparison with other irrigating solutions on the middle third of instrumented root canal using SEM showed that $2 \%$ chitosan acetate was effective in eliminating the smear layer as $17 \%$ EDTA and the use of $2 \%$ chitosan acetate followed by $\mathrm{NaOCl}$ produced clean surface. These results suggested that chitosan is a promising chelating agent ${ }^{(10)}$. The effect of chitosan acetate at various concentrations on the elimination of the smear layer on dentin was evaluated. The results showed that $0.2 \%$ chitosan for 3 min effective for eliminating the smear layer ${ }^{(11)}$.

A recent study compared the smear layer removal from root canal dentin subjected to two root canal irrigants; $0.6 \%$ chitosan citrate and $17 \%$ EDTA using SEM. The results showed that $0.6 \%$ chitosan and 17\% EDTA showed similar effects in reducing the smear layer and removing dentin plugs ${ }^{(12)}$. consequently, the intend of the current study was directed to assess the chelating potential of chitosan citrate and chitosan acetate on removing smear layer.

\section{MATERIALS AND METHODS}

\section{Teeth collection and preparation:}

Sixty extracted human single rooted lower premolars with completely formed roots were collected and decapitated via diamond disc and the root length was standardized to be $16 \mathrm{~mm}$. The working length was measured by subtracting $1 \mathrm{~mm}$ from length when the end of \#10 K-files became observed at the apical foramina .

Fifty-five samples were instrumented with Revo-S Ni-Ti rotary files which were used in a 
crown-down manner. Root canal preparation was done starting with SC1 file (\# 25, 0.06 taper) which was used to $2 / 3$ of the working length with downward and a slow movement in a free progression and without pressure, followed by SC2 file (\# 25,0.04 taper) which was used to the working length with a progressive 3 waves movement (up and down movement) and followed by SU file (\# 25, 0.06 taper).AS 30 file (\# 30,0.06 taper) was used without apical pressure, after using the SU file and the apical preparation was completed using AS35(\# 35, 0.06 taper) as master apical file (MAF) ${ }^{(13)}$.

After each instrument use, irrigation with $2 \mathrm{ml}$ of freshly prepared $2.6 \%$ sodium hypochlorite for 1 minute dispensed through a 31 gauge side vent irrigating needle. At the end of preparation, the canals were irrigated with $10 \mathrm{ml}$ distilled water.

\section{Preparation of solutions:}

\section{a. Chitosan acetate solution (0.2\%):}

Preparation of $0.2 \%$ chitosan acetate solution was performed via $0.2 \mathrm{~g}$ of chitosan powder (Sigma Co., Egypt) diluted in $100 \mathrm{ml}$ of $1 \%$ acetic acid and the mixture was stirred using a magnetic stirrer for $2 \mathrm{~h}$. It was saved in the refrigerator and used within two weeks after preparation ${ }^{(11,14)}$.

\section{b. Citric acid (1\%):}

Preparation of $1 \%$ citric acid solution was performed using $1 \mathrm{~g}$ of citric acid salt diluted in $100 \mathrm{ml}$ of distilled water.

\section{c. Chitosan citrate solution (0.2\%):}

Preparation of $0.2 \%$ chitosan citrate was performed via $0.2 \mathrm{~g}$ of chitosan powder diluted in $100 \mathrm{ml}$ of $1 \%$ citric acid and the mixture was stirred using a magnetic stirrer for $2 \mathrm{~h}$. it was saved in the refrigerator and used within two weeks after preparation.

\section{Samples grouping:}

After root canal preparation, the samples were distributed through 5 experimental groups (I, II, III,IV,V) according to the final rinse used and control group (VI) (10 samples each). Group I: irrigated with $0.2 \%$ chitosan acetate, Group II: irrigated with $0.2 \%$ chitosan citrate, Group III: irrigated with $1 \%$ acetic acid, Group IV: irrigated with $1 \%$ citric acid, Group V: irrigated with 17\% EDTA and control group which was divided into:(VIa) 5 samples irrigated with sterile saline and (VIb): 5 samples were neither prepared nor received any treatment. Each group was irrigated using $5 \mathrm{ml}$ of the irrigant for $3 \mathrm{~min}^{(11,15)}$, then all samples were received $5 \mathrm{ml}$ of distilled water and desiccated by utilizing paper points.

\section{Environmental scanning electron microscopic (ESEM) evaluation:}

All samples were grooved longitudinally in buccolingual direction without reaching the internal portion of the canal and sectioned with sharp chisel. Every sample was separated into three segments (coronal, middle and apical) and the cleanliness of the root canals and smear layer elimination were evaluated at the center of three levels of root canal using environmental scanning electron microscope (Quanta 250 FEG ESEM). Photomicrographs were taken under magnification (2000 X) for smear layer scores at three root levels and analyzed by means of numerical evaluation scores by Hülsmann et al (1997) ${ }^{(16)}$ as subsequent:

Score 1: No smear layer, dentinal tubules open. Score 2: Small amount of smear layer, some dentinal tubules open. Score 3: Homogenous smear layer covering the root canal wall, only few dentinal tubules open. Score 4: Complete root canal wall covered by homogenous smear layer, no open dentinal tubules. Score 5: Heavy, non-homogenous smear layer covering the complete root canal wall 


\section{Calcium content measurement:}

The calcium content of intraradicular dentin of five samples from each experimental groups and the samples of control group (VIa and VIb) was measured using EDX. Elemental composition and distribution were analyzed from the central region of each sample using electron beam spot size lower than $50 \mathrm{~nm}$, accelerating voltage of $30 \mathrm{kv}$ and $110 \mathrm{~mA}$.

\section{Statistical analysis:}

For parametric results; data were represented as standard deviation (SD)and mean value. For non-parametric results; data were represented as the minimum, maximum and median scores. For parametric data; Tukey's post hoc test was used for pair-wise comparisons in case of ANOVA test was significant. For non-parametric data; KruskalWallis test was used to compare among the groups. Friedman's test was used to judge between root levels within each group. Dunn's test was used for pair-wise comparisons in case of Kruskal-Wallis test or Friedman's test was significant at $\mathrm{P} \leq 0.05$.

\section{RESULTS}

I. Smear layer removal results. All data were nonparametric.

\section{I.1 Comparison of smear layer scores among the tested groups at each root level:}

\section{At coronal level:}

Kruskal-Wallis test showed that, there was a statistical difference among the tested groups and the control group in the median scores of smear layer $(\mathrm{P}<0.001)$. Dunn's test showed that, the lowest median score of smear layer was recorded in specimens treated with $0.2 \%$ chitosan acetate, $0.2 \%$ chitosan citrate and $17 \%$ EDTA. However, no statistical difference in the median scores among $0.2 \%$ chitosan acetate, $0.2 \%$ chitosan citrate, $1 \%$ acetic acid,1\% citric acid and 17\% EDTA (Table 1) and (Fig.1).

\section{At the middle level:}

Kruskal-Wallis test showed that, there was a statistical difference among the tested groups and the control group in the median scores of smear layer ( $\mathrm{P}<0.001)$. Dunn's test showed that, the lowest median score of smear layer was recorded in specimens treated with $0.2 \%$ chitosan citrate, $1 \%$ citric acid and17\% EDTA. However, no statistical difference among tested groups (Table 1) and (Fig.1).

\section{At the apical level:}

Kruskal-Wallis test showed that, there was a statistical difference among the tested groups and the control group in the median scores of smear layer ( $\mathrm{P}=0.001)$. Dunn's test showed that, the lowest median score of smear layer was recorded in specimens treated with $0.2 \%$ chitosan citrate. However, no statistical significant difference among tested groups(Table 1) and (Fig.1,2).

\section{I.2 Comparison of smear layer scores within each tested group:}

Comparing the smear layer scores within each tested group, there was a statistically difference among the three root levels in the median scores of smear layer, where the apical level has the highest median smear layer score compared to other two levels. However, no statistical difference between middle and coronal levels (Table 1). 
Table (1): Minimum, maximum and median of smear layer scores comparing the tested irrigants and control group at three root levels.

\begin{tabular}{|c|c|c|c|c|c|c|c|c|c|c|c|c|c|c|c|c|c|c|c|}
\hline \multirow{2}{*}{$\begin{array}{l}\text { Root } \\
\text { level }\end{array}$} & \multicolumn{3}{|c|}{$\begin{array}{c}\text { Group I } \\
(0.2 \% \text { chitosan } \\
\text { acetate })\end{array}$} & \multicolumn{3}{|c|}{$\begin{array}{c}\text { Group II } \\
(0.2 \% \text { chitosan } \\
\text { Citrate })\end{array}$} & \multicolumn{3}{|c|}{$\begin{array}{c}\text { Group III } \\
(1 \% \text { acetic acid })\end{array}$} & \multicolumn{3}{|c|}{$\begin{array}{c}\text { Group IV } \\
\text { (1\% citric acid })\end{array}$} & \multicolumn{3}{|c|}{$\begin{array}{c}\text { Group V } \\
(17 \% \text { EDTA })\end{array}$} & \multicolumn{3}{|c|}{$\begin{array}{l}\text { Group VIa } \\
\text { (Saline) }\end{array}$} & \multirow[t]{2}{*}{ P-value } \\
\hline & Mini & Max & Median & Mini & Max & Median & Mini & $\operatorname{Max}$ & Median & Mini & Max & Median & Mini & Max & Median & Mini & Max & Median & \\
\hline Coronal & 1 & 2 & $1^{\mathrm{B}}$ & 1 & 2 & $1^{\mathrm{B}}$ & 1 & 2 & $2^{\mathrm{B}}$ & 1 & 2 & $1.5^{\mathrm{B}}$ & 1 & 2 & $1^{\mathrm{B}}$ & 3 & 4 & $4^{\mathrm{A}}$ & $<0.001^{*}$ \\
\hline Middle & 1 & 2 & $1.5^{\mathrm{B}}$ & 1 & 2 & $1^{\mathrm{B}}$ & 1 & 3 & $2^{\mathrm{B}}$ & 1 & 2 & $1^{\mathrm{B}}$ & 1 & 2 & $1^{\mathrm{B}}$ & 4 & 5 & $4^{\mathrm{A}}$ & $<0.001 *$ \\
\hline Apical & 2 & 3 & $3^{\mathrm{B}}$ & 2 & 3 & $2^{\mathrm{B}}$ & 2 & 3 & $3^{\mathrm{B}}$ & 2 & 3 & $3^{\mathrm{B}}$ & 2 & 3 & $2.5^{\mathrm{B}}$ & 5 & 5 & $5^{\mathrm{A}}$ & $0.001 *$ \\
\hline Overall & 1.33 & 2 & $1.67^{\mathrm{B}}$ & 1.3 & 2.3 & $1.67^{\mathrm{B}}$ & 1.67 & 2.67 & $2.33^{\mathrm{B}}$ & 1.33 & 2.33 & $1.83^{\mathrm{B}}$ & 1.33 & 2 & $1.67^{\mathrm{B}}$ & 4.33 & 4.33 & $4.33^{\mathrm{A}}$ & $<0.001^{*}$ \\
\hline
\end{tabular}

*: Significant at $P \leq 0.05$

Figure (2): A scanning photomicrograph of the apical level of a root canal rinsed with(a) $0.2 \%$ chitosan acetate showing few open dentinal tubules and most of dentinal tubules partially masked with smear layer (Score 3, X 2000) (b) $0.2 \%$ chitosan citrate showing some open dentinal tubules and the rest were partially closed with smear plug (Score2, X 2000) (c)17\%EDTA showing some open dentinal tubules and the rest closed with smear plug (Score2, X 2000).

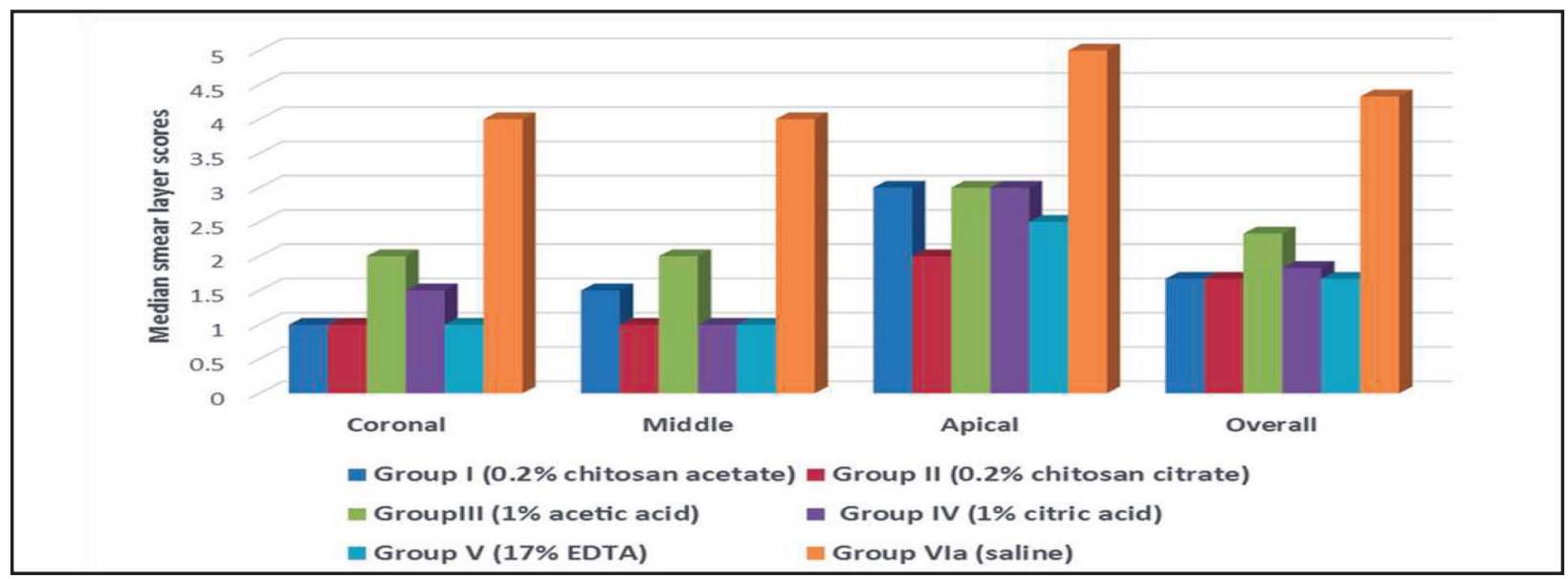

Figure(1) A bar chart comparing the median smr scores of $0.2 \%$ chitosan acetate, $0.2 \%$ chitosan citrate, $1 \%$ acetic acid, $1 \%$ citric acid, $17 \%$ EDTA and saline groups at three root levels.

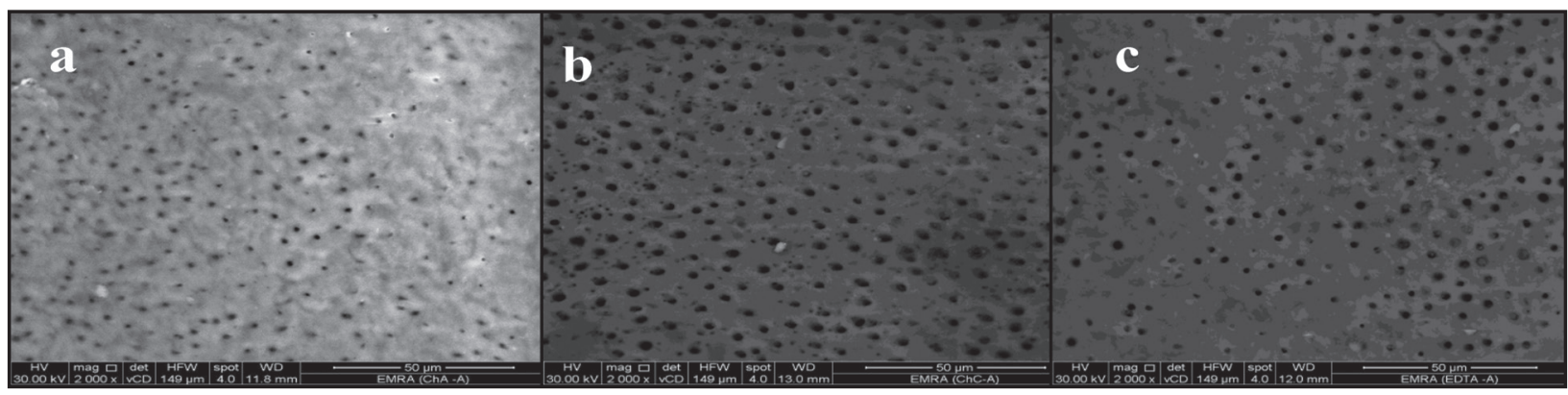

Figure(1) A scanning photomicrograph of the apical level of a root canal rinsed with(a) $0.2 \%$ chitosan acetate showing few open dentinal tubules and most of dentinal tubules partially masked with smear layer (Score 3, X 2000) (b) $0.2 \%$ chitosan citrate showing some open dentinal tubules and the rest were partially closed with smear plug (Score2, X 2000) (c)17\%EDTA showing some open dentinal tubules and the rest closed with smear plug (Score2, X 2000). 
II. Calcium content: All data were parametric.

\section{II.1 comparison of mean and standard deviation calcium content among the tested groups:}

The highest mean calcium content was recorded in samples treated with saline followed by samples that did not receive any irrigation with a statistical difference between them. The lowest mean calcium content was recorded in samples treated with $17 \%$ EDTA However, no statistical difference among $0.2 \%$ chitosan acetate, $0.2 \%$ chitosan citrate, $1 \%$ acetic acid, $1 \%$ citric acid, 17\% EDTA (Table 2).

Table (2): Mean values and standard deviation (SD) of calcium content among the tested groups.

\begin{tabular}{|c|c|c|c|}
\hline Group & Mean & $\mathrm{SD}$ & P-value \\
\hline Group I ( $0.2 \%$ chitosan acetate $)$ & $30.81^{\mathrm{c}}$ & 1.96 & \multirow{7}{*}{$<0.001 *$} \\
\hline Group II ( $0.2 \%$ chitosan citrate) & $30.52^{\mathrm{c}}$ & 2.33 & \\
\hline Group III ( $1 \%$ acetic acid) & $30.99^{c}$ & 1.33 & \\
\hline Group IV ( $1 \%$ citric acid) & $29.72^{c}$ & 1.45 & \\
\hline Group V (17\% EDTA) & $27.81^{\mathrm{c}}$ & 1.19 & \\
\hline Group VI a (saline) & $39.59^{\mathrm{a}}$ & 4.46 & \\
\hline Group VI b (no treatment) & $36.00^{\mathrm{b}}$ & 4.49 & \\
\hline
\end{tabular}

*: Significant at $P \leq 0.05$

\section{DISCUSSION}

Root canal instrumentation produces smear layer, as it contain microorganisms and their byproducts, prevent entrance of irrigation into dentinal tubules and affected on the efficacy of filling materials to canal walls so it affected on treatment outcome ${ }^{(17)}$. The searching for an perfect root canal irrigant continues with the progress of newer materials and methods. Consequently, the current study was directed to assess the chelating potential of chitosan citrate and chitosan acetate on removing smear layer using ESEM and quantify the calcium content of intraradicular dentin using EDX.

In present study, the result showed that, the lowest median score of smear layer at the coronal level was recorded in specimens treated with $0.2 \%$ chitosan acetate, $0.2 \%$ chitosan citrate and $17 \%$ EDTA. However, no statistical difference in the median scores of smear layer among the tested groups.

The efficiency of chitosan for smear layer elimination could be due to the hydroplilic nature of chitosan which favors its intimate contact with root canal dentin and its adsorption to root canal wall. It has large number of amino groups and free hydroxyl that make it cationic in nature and this is responsible for the ionic interaction between the calcium ions and chitosan ${ }^{(18)}$.

The lowest median score of smear layer that was recorded in specimens treated with $0.2 \%$ chitosan acetate, $0.2 \%$ chitosan citrate compared to that of $1 \%$ acetic acid and $1 \%$ citric acid, promoted a superior smear layer removal capacity of $0.2 \%$ chitosan acetate and $0.2 \%$ chitosan citrate solutions. This point is essential because the chitosan acetate and chitosan citrate solutions used in the present study were performed using $1 \%$ acetic acid and $1 \%$ citric acid respectively. Thus, it is obvious that the smear layer elimination is owing to chelating action of chitosan and not to that of $1 \%$ acetic acid or $1 \%$ citric acid.

The current study was in agreement with preceding study which revealed that $0.2 \%$ chitosan acetate and $15 \%$ EDTA had comparable smear layer elimination capacity with a considerable difference from $1 \%$ acetic acid ${ }^{(19)}$.The current study was in disagreement with a recent study, which reported that, $0.2 \%$ chitosan acetate was unsuccessful in elimination of the smear layer in the three root level ${ }^{(20)}$, this could be attributed to using chitosan solution with less contact time (1 $\mathrm{min})$.

Regarding the middle level, the lowest median score of smear layer was recorded in specimens treated with $0.2 \%$ chitosan citrate, $1 \%$ citric acid and $17 \%$ EDTA. However, there was no statistical difference in the median scores of smear layer among the tested groups. 
The chelation potential of chitosan based on the $\mathrm{pH}$ of the solution and ions involved ${ }^{(18)}$. In the present study, $0.2 \%$ chitosan citrate showed decrease in the $\mathrm{pH}(2.27)$ compared to that $0.2 \%$ chitosan acetate (2.98) and $1 \%$ citric acid showed decrease in $\mathrm{pH}$ (2.4) compared to that of $1 \%$ acetic acid (2.64). Therefore, $0.2 \%$ chitosan citrate and $1 \%$ citric acid have more chelating potential than $0.2 \%$ chitosan acetate and $1 \%$ acetic acid respectively. Additionally there are difference between the two solvents, where acetic acid $\left(\mathrm{CH}_{3} \mathrm{COOH}\right)$ is weak monobasic acid, which has one replaceable hydrogen atom that can bind to calcium ion but it does not have the concentration of $\mathrm{H}^{+}$ions that could produce an efficient calcium removal. While citric acid $\left(\mathrm{C}_{3} \mathrm{H}_{5} \mathrm{O}(\mathrm{COOH})_{3}\right)$, is tribasic acid, which has three replaceable hydrogen atom, that can release three protons $\left(\mathrm{H}^{+}\right)$per molecule ${ }^{(21)}$.

In the current study, the high chelating effectiveness of $0.2 \%$ chitosan citrate was agreement with previous study, which reported that $0.1 \%$ and $0.6 \%$ chitosan solution dissolved in $1 \%$ citric acid was very efficient in eliminating the smear layer ${ }^{(22)}$. On the other hand, the results of this study were in disagreement with another study, which revealed that chelating ability of $0.2 \%$ chitosan diluted in $1 \%$ acetic acid was higher than $0.2 \%$ chitosan diluted in $3.3 \%$ citric acid. These discrepancies might be attributed to using different evaluation method (colorimetric analysis) $^{(23)}$.

Similar chelating potential of $1 \%$ citric acid and $17 \%$ EDTA reported in the present study was inconsistent with previous study, which revealed that $1 \%$ and $10 \%$ citric acid at $\mathrm{pH} 2.2$ and 1.8 respectively were more effective than $17 \%$ EDTA for smear layer removal ${ }^{(24)}$. This might be attributed to the use of chelating agent for prolonged contact time $(5,10,15$ minutes) than the current study and the use of different methodology (immersion of specimens in the solution).

Regarding apical third, the lowest median score of smear layer was recorded in specimens treated with $0.2 \%$ chitosan citrate followed by $17 \%$ EDTA. However, there was no statistical difference in the median scores of smear layer among the tested groups.

The efficiency of $0.2 \%$ chitosan citrate for smear layer removal at the apical third could be attributed to its chelating capacity. Moreover, the viscosity of the solution is another important factor, where $0.2 \%$ chitosan citrate has low viscosity that allow the solution to penetrate the dentinal tubules, therefore enhance its smear layer elimination capacity. The current study was in agreement with a recent study, which revealed that $0.6 \%$ chitosan-citrate $(0.6 \mathrm{mg}$ of the chitosan powder diluted in $100 \mathrm{ml}$ of $1 \%$ citric acid) remove the smear layer in root canal treatment is comparable with $17 \%$ EDTA $^{(12)}$.

In all tested groups, the apical level has the highest median of smear layer score compared to other two levels. ESEM observation of the dentinal wall of all samples revealed that, they have more smear layer at this third compared to coronal two thirds. This was possibly attributed to the decrease of dentinal tubules diameter and the run of the fluid, which were found to be poor in this third ${ }^{(25,26)}$. This was confirmed by a previous study, which concluded that greater amounts of smear layer were found at the apical third of the canal ${ }^{(27)}$. Moreover, it has been proven that there was a definite decrease in the effectiveness of the irrigating solutions due to dentin at this third is sclerosed ${ }^{(28)}$.

The highest mean calcium content that was recorded in group VIa (Saline) compared to group VIb (did not receive any irrigation) could be explained by the variable effect of $\mathrm{NaOCl}$ as irrigating solution on mineral content of root dentin, where it may causes mineral gathering in root dentin ${ }^{(29)}$.

Regarding the lower mean calcium content recorded in samples treated 17\% EDTA compared to that recorded in samples treated with $0.2 \%$ chitosan acetate, the results were in concurrence with preceding study, which reported that the $\mathrm{Ca} / \mathrm{P}$ 
ratio of $17 \%$ EDTA group is lower than that of $0.2 \%$ and $0.5 \%$ chitosan acetate solutions at three root level $^{(30)}$.

The current study reported that, no statistical difference among the tested groups in the mean calcium content. This finding was in agreement with a recent study, which reported that $0.2 \%$ chitosan acetate is equally effective to $17 \%$ EDTA in removing $\mathrm{Ca}$ ions from root dentin ${ }^{(31)}$.

\section{CONCLUSION}

1. Chitosan as a natural product in the form of acetate or citrate is a promising chelating agent.

2. The chelating potential of $0.2 \%$ chitosan acetate and $0.2 \%$ chitosan citrate is comparable to that of $17 \%$ EDTA.

3. The effect of $0.2 \%$ chitosan acetate and $0.2 \%$ chitosan citrate was equal in removing $\mathrm{Ca}$ ions from root canal dentin without much altering calcium content of intraradicular dentin compared to $17 \%$ EDTA.

\section{REFERENCES}

1. Violich DR, Chandler NP. The smear layer in endodontics: a review. Int Endod J 2010; 43: 2-15.

2. Torabinejad M, Handysides R, Khademi AA. Clinical implications of the smear layer in endodontics: a review. Oral Surg Oral Med Oral Pathol Oral Radiol Endod 2002;94: 658-66.

3. Calt S and Serper A. Time-dependent effects of EDTA on dentin structures. J Endod 2002; 28:17-9.

4. Segura JJ, Calvo JR, Guerrero JM, Sampedro C, Jimenez A, et al. The disodium salt of EDTA inhibits the binding of vasoactive intestinal peptide to macrophage membranes: Endodontic implications. J Endod 1996; 22:337-40.

5. JÚNIOR, Roberto Trujillo. Biocompatibility of citric acid in different concentrations- edemogenic test. Salusvita, Bauru 2003; 22: 181-90.

6. Machado R, Garcia LFR, Neto UXS, Filho AMC, Silva RG, et al. Evaluation of $17 \%$ EDTA and $10 \%$ citric acid in smear layer removal and tubular dentin sealer penetration. Microsc Res Tech 2018; 81: 275-82.
7. De-Deus G, Souza EM, Marins JR, Reis C, Paciornik S, Zehnder M. Smear layer dissolution by peracetic acid of low concentration. Int Endod J 2011; 44:485-90.

8. Kurita K. Chemistry and application of chitin and chitosan. Polyme Degrad Stabil. 1998; 59: 117-20.

9. Pillai CKS, Paul W, Sharma CP. Chitin and chitosan polymers: Chemistry, solubility and fiber formation. Prog Polym Sci 2009 ;34:641.

10. Fawzy MI. Scanning electron microscopic evaluation of the effectiveness of chitosan solution in smear layer removal. Egy Dent J 2011; 57:419-24.

11. Silva PV, Guedes DF, Pécora JD, Cruz-Filho AM. Timedependent effects of chitosan on dentin structures. Braz Dent J 2012; 23: 357-61.

12. Gusiyska A, Vassileva R, Dyulgerova E, Ilieva R, Mironova J, et. al . The Effectiveness of a Chitosan-Citrate Solution to Remove the Smear Layer in Root Canal Treatment- An in-vitro study.JSR 2016;5:1169-74.

13. Revo S brochure. Available at WWW. revo-S.com.

14. Da cruz-Filho AM, De Vito Bordin AR, Souza-Flamini LE, Dacosta Guedes DF, et al. Analysis of the shelf life of chitosan stored in different types of packing, using colorimetry and dentine microhardness. Rest Dent Endod 2017; 42: 87-94

15. Mello I, Kammerer BA, Yoshimoto D, Macedo MC, Antoniazzi JH. Influence of final rinse technique on ability of ethylenediaminetetraacetic acid of removing smear layer. J Endod. 2010;36:512-4.

16. Hülsmann M, Rümmelin C, Schäfers F. Root canal cleanliness after preparation with different endodontic handpieces and hand instrument. A comparative SEM investigation. J Endod 1997; 23:301-6.

17. Sonu K R, Girish T N, Ponnappa K C, Kishan K V, Thameem PK. Comparative evaluation of dentinal penetration of three different endodontic sealers with and without smear layer removal - Scanning electron microscopic study. Saudi Endod J 2016;6:16-20.

18. Rahzi M, Desbriéres J, Tolaimate A, Rinaudo M, Vottero $\mathrm{P}$, et al. Influence of the nature of the metal ions on the complexation with chitosan: Application to the treatment of liquid waste. Euro Polymer J 2002; 38: 1523-30.

19. Silva PV, Guedes DFC, Nakadi FV, Pecora JD, Cruz-Filho AM. Chitosan: a new solution for removal of smear layer after root canal instrumentation. Int Endod J 2013; 46: $332-8$. 
20. Vallabhaneni K, KaKarla P, Avula SJ, Reddy VG, Gowd $\mathrm{MP}$, et al. Comparative analyses of smear layer removal using four different irrigant solutions in the primary root canals - SEM study. J Clinic Diagno Res 2017; 11: 64-7.

21. Goldberg R, Kishore N, Lennen R. Thermodynamic Quantities for the Ionization Reactions of Buffers. J. Phys Chem Ref Data 2002; 31 :231-370.

22. Gusiyska A, Vassileva R, Dyulgerova E, Ilieva R, Mironova J, Gyulbenkiyan E. Scanning Electron Microscopy Studies of Root Canal Dentin Irrigated with a Chitosan-Citrate Solution: A Preliminary Report. IJSR 2016;5:539-42.

23. Silva PC, Souza-Flamini, Guedes DF, Pécora JD, CruzFilhoAM. Evaluation of the chelating effect of chitosan solubilized in different acids. J Consrev Dent 2017;20:297-301 .

24. Machado-Silveiro LH, Gonzalez-Lopez S, GonzalezRodriguez MP. Decalcification of root canal dentin by citric acid, EDTA and sodium citrate. Int Endod J 2004; 37 : 365-9.

25. Mancini M, Armellin E, Casaglia A, Cerroni L and Cianconi L.A comparative study of smear layer removal and erosion in apical intraradicular dentine with three irrigating solutions: a scanning electron microscopy evaluation. J Endod 2009;35: 900-3.
26. Brunson M, Heilborn C, Johnson DJ, Cohenca N. Effect of apical preparation size and preparation taper on irrigant volume delivered by using negative pressure irrigation system. J Endod 2010; 36: 721-4.

27. Gulabivala K, Ng Y-L, Gilbertson M, Eames I. The fluid mechanics of root canal irrigation. Physiol Meas. 2010; 31:49-84.

28. Vasiliadis L, Darling AL, Levers BG. The amount and distribution of sclerotic human dentin. Arch Oral Biol 1983; 28: 645-9.

29. Inaba D, Ruben J, Takagi O, Arends J. Effect of sodium hypochlorite treatment on remineralization of human root dentine in vitro Caries Res 1996; 30: 218-24.

30. Mathew SP, Pai VS, Nadig RR. Comparative evaluation of smear layer removal by chitosan and ethylenediaminetetraacetic acid when used as irrigant and its effect on root dentine: An in vitro atomic force microscopic and energy-dispersive X-ray analysis. J Conserv Dent 2017; 20: 245-50

31. Bastawy HA and Ezzat R. Impact of chitosan as chelating agent on microhardness and mineral content of intraradicular dentin. Al Azhar Dent J for Girls 2016; 1: 4879-89. 